\title{
VUELTA AVANT LA
} LETTRE

Jaime Perales*

Ésta es una versión modificada del segundo capítulo de mi tesis de licenciatura sobre la revista Vuelta, ${ }^{1}$ que se defendió en abril de 1990, en el Instituto Tecnológico Autónomo de México. Resume muy brevemente la historia cultural de América Latina a través de la perspectiva particular de las publicaciones culturales y literarias de la época, desde los años veinte hasta que Octavio Paz funda Plural en la década del setenta. Las publicaciones que se mencionan son los antecedentes que abren un espacio muy importante, no sólo para la ahora célebre Vuelta, sino para las distintas publicaciones culturales latinoamericanas actuales.

\section{Contemporáneos (1928-1931)}

Contemporáneos aprendió dos lecciones que la publicación de José Ortega y Gasset, Revista de Occidente, había difundido en toda América Latina. El filósofo español divulgó en su revista a los pensadores más destacados de Alemania de esos años, como Alfred y Max Weber, Max Scheler y Georg Simmel entre otros. Contemporáneos adoptaría las ideas de Revista de Occidente, no tanto en el plano filosófico o en el

* Egresado del ITAM, realiza estudios de doctorado en Georgetown University.

${ }^{1}$ Vuelta: origen y desarrollo de una revista intelectual (1976-1986), fue el primer trabajo extenso escrito sobre la publicación de Octavio Paz. 
de la historia de las ideas, como en el literario. La segunda lección para Contemporáneos fue la actitud que tuvo Ortega y Gasset hacia la política. Ortega diría en el primer número de su revista, que la política era una categoría inferior de la cultura universal, dado que no aspiraba a comprender las cosas, y que, por lo tanto, el intelectual debía de concentrar más su atención en la obra personal. De cierta manera postulaba la actitud liberal e individualista de distancia del intelectual hacia el poder que adoptarían distintos grupos culturales, como Sur o la propia Contemporáneos. Es difícil establecer si Ortega, cuando escribió esa introducción había leído las dos famosas conferencias sobre 'ciencia y política’ como vocaciones que Max Weber dictó en Munich en 1918. Aunque algunos especialistas afirman que la posición de Ortega hacia la política no era tanto teórica como de amargura y desilusión: había participado activamente en España como fundador de la Liga de Educación Política en 1913, el semanario España en 1914 y 1915 y la editorial Espasa Calpe en 1919, pero en todas estas empresas la política siempre había sido un problema, que llegó a su clímax con la dictadura de Primo de Rivera. Fue en estas circunstancias que Ortega pensó que el intelectual debía limitarse a las cuestiones eternas de la cultura y el conocimiento. Contemporáneos adoptó la posición, sin embargo para sus integrantes el sector político fue un refugio. La mayoría alcanzó cierto éxito con algunos puestos en la burocracia mexicana: Salvador Novo y Carlos Pellicer fueron secretarios particulares de Narciso Bassols y José Vasconcelos cuando éstos eran Secretarios de Educación; José Gorostiza fue de Relaciones Exteriores durante el régimen de Ruiz Cortines y Jaime Torres Bodet de Educación durante el gobierno de Ávila Camacho. Los Contemporáneos despreciaban a la política, pero estaban conscientes que en México era difícil sobrevivir sin ella. (Se puede recordar la frase despectiva de Novo: "En México todo sucede de acuerdo a la eyaculación espasmódica de la política.”)

Otra diferencia importante de Contemporáneos, con respecto a $R e$ vista de Occidente, fue su preferencia por una estética afrancesada. Algunos miembros del grupo, como Jorge Cuesta, consideraron que la 
cultura francesa no era una presencia 'artificial', dado que había existido por más de un siglo en México. Por lo tanto, era tarea del escritor difundirla a través de la creación y el ensayo artístico. Al contrario, la publicación de Ortega y Gasset siempre tuvo una posición de reserva con respecto a Francia y su literatura, dado que en ese momento la modernidad se encontraba en Alemania. La posición de Contemporáneos hacia Francia sólo se podía explicar por el marco cultural de América Latina en el primer tercio del siglo Xx y la actitud que tuvieron algunas revistas culturales hacia la vanguardia europea. Por ejemplo, en Argentina Sur tuvo una posición favorable hacia Europa, sobre todo Francia. En el primer número su fundadora, Victoria Ocampo, en una carta dirigida a Waldo Frank consideró que la creación de una revista cultural era un elemento esencial para que se estableciera un diálogo entre "América” y Europa. El volverle la espalda a Europa para Victoria Ocampo era una consideración más que absurda. El ensayo y la creación artística de la nueva vanguardia europea francesa fueron los dos polos esenciales que sostuvieron a Sur en sus primeros años de vida.

Por su parte, en Perú, la revista fundada por José Carlos Mariátegui, Amauta (1926-1930), buscó fundir el radicalismo político con la vanguardia europea del momento. En el caso de Cuba, la revista de Alejo Carpentier, Jorge Manach y Juan Marinello, Avance (1927-1930), buscó también de establecer un diálogo cultural entre América Latina y Europa. En Brasil, revistas como Klaxon, Terra Roxa y Verde establecieron los más finos debates culturales y manifiestos a favor de la cultura europea de vanguardia. Obras como Macunaima de Mario de Andrade mezclaron el modernismo europeo con la conciencia de la etnicidad brasileña.

El juicio de Octavio Paz sobre Contemporáneos rebasó la línea de la promoción de la vanguardia estética y se dirigió más hacia una interpretación moral. En un programa de televisión difundido en México, con motivo del aniversario de los diez años de la revista Vuelta, Paz resumió una idea importante desarrollada en dos ensayos donde se destacaba la actitud de difusión del grupo: La posición de defensa hacia la vanguardia europea de Contemporáneos era una afrenta políti- 


\section{JAIME PERALES}

ca y moral contra una estética impositiva surgida en un marco nacionalista donde los distintos grupos emergentes de la Revolución mexicana eran cooptados por el Estado. El discurso nacionalista de José Vasconcelos, que se cristalizó en el muralismo mexicano, fue un instrumento del Estado para difundir una estética que exaltara exclusivamente la Revolución mexicana. Mientras que la actitud revolucionaria para Contemporáneos, no era una categoría política, sino un concepto vital cuya mejor manifestación era el arte. Gilberto Owen, uno de sus fundadores, se refirió a esta particular forma de vivir: "Todos éramos, original, esencialmente revolucionarios (...) Nacidos, crecidos en respirar aquel aire de adoptar posturas nuevas ante la vida. Sentíamos esto lo único revolucionario y más sincero que tomar simplemente lo viejo y barnizarlo y escribir encima: Viva la Revolución!”

La respuesta de los Contemporáneos era, en cierta forma, una de las distintas reacciones de la sociedad civil ante un Estado aún difícil de ser asimilado por los distintos grupos sociales que estaban surgiendo de la Revolución mexicana.

El último número de Contemporáneos mencionó a Barandal (19311932), la primera revista en que Octavio Paz fue cofundador y miembro del consejo de redacción. El comentario de Ortiz de Montellano era, además de un reconocimiento, la adopción cultural de un grupo de escritores que se estaba formando en el medio literario mexicano y que, en cierta manera, seguía los pasos de Contemporáneos:

"En sus cuatro años de existencia Contemporáneos, se ha visto confortada con la aparición de algunas revistas de principios semejantes a los nuestros. Primero Bandera de Provincia y Campo, ahora Barandal, apoyo de una generación próxima y cercana -cuatro nombres: Octavio Paz, Rafael López, Arnulfo Martínez Lavalle y Salvador Toscano- que con buen gusto y seguridad inteligente nuestro aislamiento llama una generación.” 
VUELTA AVANT LA LETTRE

\section{Taller (1938-1941)}

Los escritores latinoamericanos que vivieron la década de los años treinta experimentaron tres fenómenos decisivos: La crisis económica generalizada y, como consecuencia la efervescencia revolucionaria y socialista que se generó en toda América Latina. La contribución del exilio español al enriquecimiento cultural latinoamericano; y el nacimiento de una nueva generación de lectores.

En los años treinta, junto a los brotes revolucionarios socialistas, que habían ganado relativamente pocos simpatizantes en la década anterior, América Latina había empezado a copiar del fascismo europeo modelos económicos intervencionistas. Esto dio como resultado que el período comprendido entre 1930 y 1945 fuera de conflictos ideológicos. Durante la década de los años treinta a todo lo largo de América Latina, se organizaron partidos comunistas con diferentes resultados regionales. Tuvieron notable presencia en Brasil, Chile y Cuba y una fuerza menor en países como Argentina, Uruguay, Colombia y Venezuela. En México, debido al apoyo del presidente Lázaro Cárdenas, el Partido comunista mexicano obtuvo una mayor presencia política debido a que dejó de ser un partido perseguido por el gobierno, como ocurrió durante la época del llamado Maximato dirigido por el ex presidente Plutarco Elías Calles (1930-1934).

En el aspecto cultural, la Guerra civil española tuvo una influencia indudable en la política cultural en América Latina, abrió sus puertas a las distintas disciplinas del conocimiento, que fueron enriquecidas por hombres de letras como Juan Ramón Jiménez, Rafael Alberti y León Felipe; editores como Gonzalo Losada y López Llausás; profesores como José Gaos y Xavier Zubiri y cineastas como Luis Buñuel. Por la talla de sus integrantes, algunos han comparado este exilio con el Renacimiento cultural italiano del cuatrocientos escapando del cerco de Constantinopla.

Finalmente, la generación de escritores latinoamericanos de principios de los treinta empezó a relacionarse con una nueva generación de 
JAIME PERALES

lectores iniciada hacia 1939 y creciente a través de un mayor número de universidades, escuelas, bibliotecas, librerías y editoriales latinoamericanas promotoras de la cultura.

América Latina de los treinta experimentó el nacimiento de numerosas revistas culturales, pero su circunstancia -económica (depresión), política (auge de partidos socialistas), cultural (influencia de pensamiento europeo)- provocaría una tensión entre literatura y política. Algunas de ellas fueron Sur, en Argentina; Orígenes, en Cuba; Número, en Uruguay; Babel, en Chile; y Taller, en México.

Ésta, al rechazar el arte puro, tomó distancia con Contemporáneos. Para Taller la crítica a la estética nacionalista impuesta por el gobierno de Elías Calles era insuficiente ante los problemas de Latinoamérica en esos años. El ensayo de Octavio Paz “Razón de ser” publicado en el segundo número de Taller era tanto un reconocimiento público como una crítica a Contemporáneos y su actitud 'purista' ante la literatura. La interpretación de la literatura de Taller tenía relación con lo que diversas revistas culturales europeas y norteamericanas entendieron como ‘compromiso político' del intelectual llamándolo de distintas formas: literatura comprometida, literatura con mensaje social, literatura para las masas, arte de tesis, vanguardia literaria o radicalismo político, entre otras. Taller fue una revista literaria con una tendencia dosificada de marxismo. Sin embargo, como dice Paz en su ensayo sobre Taller, la revista se había formado con distintas interpretaciones del marxismo de la época: José Revueltas se inclinó por las ideas de Lenin; José Alvarado y Efraín Huerta por Stalin y el propio Paz se consideró en ese momento influenciado por las ideas de Trotsky. Taller interpretó la idea de 'escritor comprometido' sostenida en Qué es la literatura? Para la línea articulada por Sartre, el intelectual debía reflexionar críticamente sobre la situación política del momento, era un agente de cambio de la sociedad.

La segunda respuesta de Taller a los problemas del momento, consistió en incluir a la generación de la revista española Hora de España, (que Paz conoció cuando fue delegado mexicano en el Segundo Congreso de Escritores Antifascistas, celebrado en Valencia), entre 
VUELTA AVANT LA LETTRE

los que se encontraban: Manuel Altolaguirre, Ramón Gaya, Juan GilAlbert, Ramón Prados y Manuel Sánchez Barbudo. (Sin embargo, Paz en su ensayo hace particular énfasis en la influencia de Luis Cernuda para su formación de poeta.)

La tercera respuesta de Taller a la nueva generación de lectores gestada en esa época, fue la traducción de escritores poco conocidos en Latinoamérica, como Rimbaud, Hölderlin, Leopardi o T.S. Eliot. Octavio Paz ha declarado con orgullo que la revista Taller fue la primera publicación latinoamericana que publicó, con expresa autorización del autor, una antología de traducciones de poemas de Eliot autor capital de Europa en esos años. También ha escrito Paz, que Taller tradujo la actitud del llamado Frente Popular Francés en términos literarios, que fundamentalmente consistió en defender la libertad del escritor frente a la ideología.

\section{EI Hijo pródigo (1943-1946)}

Las dos revistas juveniles más importantes Taller y Tierra nueva pronto concluyeron su existencia. En el panorama cultural mexicano de los años cuarenta encontramos Letras de México (1937-1948) y Cuadernos americanos (1942-), revista fundada por el economista y abogado Jesús Silva Herzog con una actitud panamericana ante la Guerra Mundial -el primer número apareció poco después del ataque a Pearl Harbor. Aunque cultivó con provecho el ensayo y la creación literaria, -la publicación fue apoyada por Alfonso Reyes, el escritor mexicano más importante de la época- se especializó en disciplinas sociales como la sociología y la economía, por lo que los escritores jóvenes de la generación de postguerra en esos años no tuvieron un espacio exclusivo para la participación literaria.

El funcionario público y editor de Letras de México, Octavio G. Barreda, tuvo la idea de fundar una publicación de 'categoría textual' donde se promoviera el espíritu creador de los nuevos escritores mexicanos, que fue El Hijo pródigo. La revista trató de diferenciarse de 
JAIME PERALES

Letras de México y Cuadernos americanos circunscritas al área geográfica de México y Latinoamérica. Para Barreda, la cultura europea debía ser defendida como un concepto importante dentro de la cultura nacional, dado que en los años cuarenta se había difundido en México el pesimismo decadentista de la Segunda guerra mundial que veía a la cultura europea liquidada como un reflejo de la crisis del capitalismo. Esta visión se reforzaba con opiniones como las de Diego Rivera, el Secretario de Educación Jaime Torres Bodet y el cónsul chileno Pablo Neruda, que defendían una literatura nacionalista. Octavio Paz, coeditor de la revista El Hijo pródigo escribió en un ensayo posterior que las ideas estéticas defendidas oficialmente los años cuarenta eran, más que todo, una máscara ideológica de la intolerancia del Estado mexicano que no permitía tendencias distintas a la suya. El Hijo pródigo fue interpretada por Paz como una continuación lógica de Taller y Hora de España que defendieran la 'libertad del arte' frente a la ideología.

El Hijo pródigo intentó ser el punto de unión entre las dos tendencias imperantes de la época -regionalismo y cosmopolitismo- como un término medio de la cultura universal. También reunió a colaboradores de distintas edades, como Alfonso Reyes, Xavier Villaurrutia, Alí Chumacero y Octavio Paz, efectuando una alianza generacional entre escritores mexicanos.

Finalmente la revista se unió a la discusión generada por la Guerra fría en torno a fórmulas establecidas en el momento como capitalismo contra socialismo y democracia contra comunismo. En el marco de este debate compartido con otras revistas culturales latinoamericanas, El Hijo pródigo, probablemente por iniciativa de Octavio Paz, publicó a algunos escritores disidentes de la Unión Soviética, como Victor Serge y Jean Malaquais.

Debido a que ganó una beca para estudiar en el extranjero, Octavio Paz fue coeditor de la revista hasta el número siete, sin embargo continuaría colaborando irregularmente hasta la desaparición de la revista. 
VUELTA AVANT LA LETTRE

\section{Sur (1931-1970)}

Octavio Paz leyó a André Bretón por primera vez en español en la revista Sur. Bretón, junto con el libro de William Blake, El matrimonio del Cielo y el Infierno, le 'abrieron las puertas de la poesía moderna'. Según John King, en su libro sobre Sur, Paz fue uno de los colaboradores extranjeros más asiduos de la revista y esto perduraría hasta que fundara la propia. Paz contribuyó en la Guerra fría con un ensayo y una antología sobre los campos de concentración soviéticos en la década de los cincuenta, también en la presentación de una selección de literatura japonesa, en colaboración con el especialista Donald Keene. La amistad de Octavio Paz con José Bianco, jefe de redacción de Sur que lo ayudó a publicar su primer ensayo fue uno de los hechos decisivos para que la generación de Sur y la de Vuelta establecieran una comunicación cercana. Por ejemplo, el escritor argentino Danubio Torres Fierro, en la primera época de Plural, entrevistaría a los principales colaboradores de Sur: Jorge Luis Borges, Adolfo Bioy Casares, José Bianco, Silvina y Victoria Ocampo. También se realizó un número especial de Vuelta en homenaje a Victoria Ocampo con motivo de su muerte en 1979, donde Octavio Paz declaró la importancia que había tenido Sur para él y muchos escritores de su generación. De igual manera, es importante recordar que durante los años de consolidación de Vuelta, Alejandro Rossi, editor de la revista en ausencia de Paz, significativamente publicó en el primer número un trabajo de Jorge Luis Borges y Adolfo Bioy Casares.

Algunos de los colaboradores de Vuelta tuvieron su primer acercamiento con la literatura europea y norteamericana de la época a través de Sur. Así como Carlos Fuentes ha comentado que tenía la impresión de conocer a Julio Cortázar mucho antes de encontrarse personalmente con él por las páginas de Sur y Mario Vargas Llosa se ha referido a la profunda influencia de la revista durante sus años de formación, dado que conoció varias obras de Sartre y Camus por las traducciones de la editorial argentina, también Guillermo Cabrera Infante reconoce la importancia de la revista para los escritores cubanos 
JAIME PERALES

de su generación. Sur fue la publicación latinoamericana más afín a Vuelta, sin embargo, pueden reconocerse diferencias importantes entre ambas en torno a la política.

Sur mantuvo la actitud de su mentor espiritual, José Ortega y Gasset, para quien política era un elemento excéntrico de la cultura y del arte: “¿Cómo podría imbricarse en la política el cuarteto para cuerdas de Debussy, la Sinfonía de los salmos de Stravinski o un pescado de Braque?” Sur siempre mantuvo una posición definida, fue antipopulista en el plano doméstico y anticomunista en el internacional, sin embargo la política fue un elemento tan importante, que llegó a provocar la renuncia de José Bianco, durante veinticinco años jefe de redacción de Sur, por diferencias con la directora Victoria Ocampo. La ética de Sur consistió en defender el liberalismo en el plano político, el individualismo en el teórico, y el elitismo cultural en el estético; sus colaboradores, a diferencia del peronismo de la época y del compromiso intelectual sostenido por Sarte, estaban convencidos de que la cultura y el arte eran minoritarios. El compromiso en Sur se orientó a rechazar todo tipo de dictadura como una manera de combatir la barrera de la ideología, independientemente del compromiso del intelectual con la política o con el arte.

A diferencia de Sur, que siempre utilizó a la literatura y al arte como formas de distanciamiento del intelectual ante el poder, para Vuelta el compromiso del intelectual ha estado orientado por la moral, y su instrumento ha sido la crítica. Para la publicación de Paz ésta es la razón que justifica que una revista cultural escriba sobre política.

\section{Revista mexicana de Literatura (1955-1963)}

A finales de los cincuenta, sus años de decadencia, Sur no pudo responder ante la nueva generación de escritores y lectores en formación. Este espacio comenzaría a ser cubierto por publicaciones surgidas en distintos puntos de Latinoamérica, como la revista de la Casa de las Américas, Marcha, Mundo nuevo y la Revista mexicana de Literatura, 
editada por Carlos Fuentes y Emmanuel Carballo en su primera época, y por Juan García Ponce y Tomás Segovia en la segunda. Las ideas directrices en los cuarenta de política y literatura adquirieron renovado vigor a finales de los cincuenta ante el entusiasmo generado por la Revolución cubana. La generación cultural latinoamericana más cercana a la Revolución cubana fue la del llamado Boom; la revista publicó los primeros textos de tres de sus flamantes protagonistas, que aún no se conformaba como grupo con lo cual se adelantó a la publicación de Emir Rodríguez Monegal, Mundo nuevo: Carlos Fuentes, Gabriel García Márquez y Julio Cortázar. La publicación tuvo la vocación latinoamericanista de Cuadernos americanos, pero al mismo tiempo cuidando la tradición universal de Sur, es decir, trató de equilibrar nacionalismo y cosmopolitismo. Las influencias clave que la Revista mexicana de Literatura había adoptado conscientemente eran las de los dos escritores mexicanos más importantes de ese momento: Alfonso Reyes y Octavio Paz, haciendo suya la observación del primero, de que la literatura latinoamericana era importante no por ser latinoamericana sino por ser literatura, independientemente de la nacionalidad y el lenguaje.

En política, la revista adoptó la idea de Emmanuel Mounier de una 'tercera vía', pero no fue la católica-marxista de Esprit en los cuarenta en Francia, sino una posición social-demócrata crítica a la hegemonía postbélica estadounidense. Por esta razón, se publicaron algunos de los representantes más significativos del pensamiento contemporáneo, que habían sido duramente criticados durante la década de los cuarenta en Europa: Bertrand Russell, Albert Camus, Jean Paul Sartre, André Malraux, Arthur Koestler, Czeslaw Milosz y E. M. Cioran. Pero uno de los pasos editoriales más importantes de la Revista mexicana de Literatura será el de iniciar la publicación de una nueva generación de escritores: Tomás Segovia, Juan García Ponce, Salvador Elizondo, José de La Colina, Marco Antonio Montes de Oca, Homero Aridjis y Gabriel Zaid. 
JAIME PERALES

\section{Una nueva generación de editores latinoamericanos (1960-1970)}

La creación de revistas culturales como Vuelta son inexplicables si no se habla del nacimiento de la compleja red de publicaciones, premios y editoriales que nacieron a finales de la década de los sesenta en América Latina y en Europa. Se ha mencionado el crecimiento demográfico de las grandes urbes latinoamericanas y, como consecuencia, una mayor demanda de libros y bibliotecas. Los exiliados en América Latina de la Guerra civil española no sólo contribuyeron en el plano de las ideas sino como empresarios culturales, especialmente fundando editoriales que difundieron la nueva literatura latinoamericana, como González Caso, López Llosa, Arnaldo Orfila y Joaquín Diez Canedo. Arnaldo Orfila, fundador de Siglo XXI, por ejemplo, dio a conocer no sólo obras de sociología sino también numerosas novedades durante la década de los sesenta, como Corriente alterna, de Octavio Paz; Todos los gatos son pardos, de Carlos Fuentes y Último round, de Julio Cortázar, entre otras obras significativas. También tradujo libros en esa época muy recientes como Las palabras y las cosas de Michel Foucault, que de este modo fue conocido, antes en castellano que en inglés. Por su parte, en 1960 Emecé de Buenos Aires empezó a reeditar toda la obra de Jorge Luis Borges, escritor minoritario hasta entonces convertido en auténtico best-seller. En Brasil, las ediciones efectuadas por José Olympo de Jorge Amado, Gracilino Rojas y José Lins de Rego hicieron que estos autores se difundieran de una manera mucho más amplia.

El éxito de algunas páginas culturales latinoamericanas fue otro elemento que ayudó a la introducción posterior de revistas intelectuales como Vuelta. Entre ellas, el suplemento cultural de Siempre en México, la sección cultural de La gaceta de Tucumán en Argentina, el suplemento de O Estado de Sao Paulo y el semanario Marcha de Montevideo, fundado por Juan Carlos Onetti.

Las pequeñas editoriales fueron otro elemento de promoción para la literatura latinoamericana, como Era en México; la Editorial Uni- 
versitaria en Chile; Jorge Álvarez y Galeano en Buenos Aires; y Arca en Montevideo.

Todos los elementos enumerados incidieron en la consolidación de la cultura latinoamericana de los años setenta, sin embargo el hecho más importante que unió y al mismo tiempo separó a toda la literatura latinoamericana contemporánea fue la Revolución cubana, que funcionaría como deslinde del compromiso ético y político del estético. Cuba, de la noche a la mañana, se convirtió en noticia. La Casa de las Américas, probablemente fue la institución cultural más importante de América Latina durante los sesenta, que publicó, con el mismo nombre, una revista consecutivamente dirigida por Fausto Masso, Antón Arrufat y Roberto Fernández Retamar. La revista organizó el llamado Premio Casa de las Américas, que por un tiempo fue un importante elemento de promoción de la nueva literatura latinoamericana.

El más destacado evento editorial ocurrido durante el franquismo, fue la fundación de la editorial Seix-Barral, por los españoles Joan Petit, José María Castellón y Carlos Barral. Por iniciativa del primero, se organizó el Premio Biblioteca Breve inaugurado en 1958 con su adjudicación a la novela de Luis Goytisolo Las afueras, y consolidado en 1962 cuando se otorgó a la novela de Mario Vargas Llosa, La ciudad y los perros. El codiciado premio por los autores de la nueva literatura latinoamericana también fue alcanzado por Los albañiles (1963) de Vicente Leñero, Tres tristes tigres (1964) de Guillermo Cabrera Infante y Cambio de piel (1967) de Carlos Fuentes. Seix Barral permitió que la nueva literatura latinoamericana fuese accesible en Latinoamérica y Europa a un público más vasto que el hasta entonces alcanzado por las pequeñas editoriales.

Mientras tanto en Francia Gallimard y Seuil crearon la colección Ouvres de la litterature latino-americaine, dirigida por Severo Sarduy y Claude Durand, entre cuyas traducciones aparecieron Cent ans de solitude de García Márquez, Paradiso de José Lezama Lima, L’obscure oiseau de la nuit de José Donoso, y La nuit hallucinant de Arenas, entre otros. 
JAIME PERALES

\section{Libre (1971)}

En 1971 apareció en Francia la publicación trimestral Libre, que no obstante su vida efímera tuvo gran importancia por el peso intelectual de sus colaboradores, que tuvieron como propósito principal escribir con el compromiso político de los grandes intelectuales 'de-la-gauche francaise’. La revista representó a un grupo de escritores inconformes con los sistemas sociales del momento, que planteó su inconformidad a través de la 'crítica necesaria y purificadora', conservando el equilibrio entre las pretensiones del arte ('cambiar la vida') y las de la política ('cambiar el mundo'). La publicación tenía la idea redentora de luchar contra 'la injusticia del sistema capitalista'. El primer número de la revista agrupó por última vez a una serie de escritores hispanoamericanos disímiles en cuanto a sus ideas políticas: Octavio Paz, Juan Goytisolo, Mario Vargas Llosa, Jorge Sempún y Gabriel García Márquez; sin embargo, lo verdaderamente interesante de Libre es que sus autores mayoritariamente exiliados políticos -y esto es importante, el exilio- tenía bien identificado al grupo de sus lectores: el público estudiantil. A tres años de los hechos de 1968 la revista intentaba recuperar la vitalidad del espíritu estudiantil a través del lenguaje. Dado que en América Latina no existía un centro fijo, la revista lo fincaba en Europa, al tiempo que afirmaba que la literatura aquí producida era cosmopolita y podía leerse más allá de sus fronteras.

Otra idea importante en Libre fue la de la independencia económica como clave para la independencia intelectual, que aunque no se alcanzó totalmente sería luego recuperada por Paz para Vuelta como una forma de mantener una distancia crítica frente a cualquier influencia de poder -principalmente gubernamental. Para Paz, Libre fue una concepción bastarda de su proyecto inicial como revista. Mientras que para Libre el principal problema de América Latina era el capitalismo estadounidense y la dependencia económica, para Vuelta se concentraba en torno a la doctrina y el Estado en ese momento no había salida al problema de la burocracia, que era visto como un decadentismo similar al obser- 
vado por Max Weber, como una peste que devoraba las instituciones democráticas. Para Libre la alternativa de América Latina se hallaba en experimentos socialistas tan diversos como el del Estado militar peruano del general Velasco Alvardo o el de Salvador Allende en Chile. Por cierto, Plural apoyaría la opción económica y política de Velasco, hasta su intolerancia de clausurar Caretas, una de las revistas de opinión más importantes del Perú. El pesimismo de Vuelta podía cifrarse en la metáfora de Max Weber, que veía a la burocracia como 'una jaula de hierro’. 
